\title{
O SUBJECTIVISMO DA FENOMENOLOGIA HUSSERLIANA E A POSSIBILIDADE DE UMA FENOMENOLOGIA "ASSUBJECTIVA"
}

\author{
Jan Patočka
}

A fenomenologia husserliana e as suas pretensões - por um lado, fornecer uma fundamentação do conhecimento definitiva, absoluta, por outro, no movimento desta fundamentação, progredir até um "ser absoluto" da consciência e conduzir a fundamentação através do recurso a esta esfera absoluta de ser ou de "pré-ser" - foram vistas como uma retomada do subjectivismo e, por isso, foram recusadas tanto no posterior desenvolvimento da própria fenomenologia como por críticos procedentes de outras orientações.

Por essa via, veio dar-se razão a um notável mal-estar da primeira geração de discípulos do mestre de Gotinga, que viram na fase transcendental do pensamento deste, que começou logo a seguir à redacção das Logische Untersuchungen, uma recaída na temática tradicional da filosofia moderna da consciência e, com isso, se viram obrigados a verificar a frustação das esperanças originais relativas a um efectivo novo começo da filosofia, a um acesso às próprias coisas, a um afastamento relativamente à concepção formal das tarefas filosóficas. A fenomenologia heideggeriana, que trouxe consigo um conceito totalmente diferente de fenómeno, contém decerto uma crítica implícita da fenomenologia transcendental husserliana e do seu recurso à consciência pura. Mas as observações de Heidegger (por exemplo, ao artigo da Enciclopédia Britânica sobre fenomenologia) nem por uma vez sequer levam essa crítica a uma forma sistemática. Uma tal formulação sistemática foi ainda menos encetada pelos outros críticos.

Segundo nos parece, a filosofia de Heidegger trouxe consigo pressupostos da mais alta importância para uma completa reformulação da fenomenologia, nomeadamente, acima de tudo, a descoberta dos pressupostos ontológicos inapercebidos da fenomenologia husserliana. Todavia, porque a filosofia própria de Heidegger assumiu uma viragem que só permitiu tratar o tema da "aparição enquanto tal" em conexão com a renovação da problemática do ser, ela não conduziu nunca, desde então, a uma retomada da problemática husserliana, se bem que esta última não pareça estar propriamente

1 (C) Jan Patočka Archive, Prague. Todos os direitos em língua portuguesa para Centro de Filosofia da Universidade de Lisboa e Pedro M. S. Alves. 
terminada e ultrapassada, mas ter antes experimentado um aprofundamento a partir de formas novas de levantar os problemas. ${ }^{2}$

Por via de um trabalho crítico longo e cuidadoso, averiguou-se que a tradição cujo peso teve como consequência a recaída de Husserl no subjectivismo foi a do cartesianismo, que lhe foi transmitido por Brentano. Não foi de modo algum, por conseguinte, a linhagem da filosofia crítica e do idealismo alemão, e as analogias com Fichte, que sempre de novo foram apontadas, não têm, portanto, qualquer significado genealógico.

Ludwig Landgrebe, que dedicou muito trabalho intelectual à elucidação destas tradições e à sua delimitação perante outras, chegou aproximadamente aos seguintes resultados (a formulação é da nossa responsabilidade): 1) a fenomenologia transcendental e a sua ideia de uma fundamentação do saber nada têm que ver com a ideia de fundamentação no transcendentalismo kantiano, no seu regresso ao eu puro, universal, da apercepção transcendental enquanto condição de possibilidade de uma acção sintética em geral; a inteira concepção do a priori e, em consequência, da ideia de fundamentação é, nos dois contextos, diferente, dedutivo-construtiva, do lado de Kant e dos kantianos, analítico-amostrante (em última instância, portanto, constatativa), do lado de Husserl. ${ }^{3}$ 2) A última fase da filosofia transcendental husserliana, o retorno ao mundo da vida enquanto tal, significa um afastamento, por parte de Husserl, do cartesianismo e de uma filosofia da consciência que se fundamente na autocerteza da consciência cartesiana, real e individual. ${ }^{4}$ Isto significa, porém, a confissão implícita de que a filosofia fenomenológica daquele período que se estende desde Vorlesungen zur Phänomenologie des inneren Zeitbewusstseins ${ }^{5}$ até Cartesianische Meditationen e Formale und

2 No quadro da fenomenologia husserliana, sejam referidas as formulações tardias, que rejeitam uma absoluta ausência de pressupostos; mais ainda, o facto, que Iso Kern sublinha (Husserl und Kant. Den Haag, 1964, p. 361), de, nomeadamente no $\$ 50$ da Krisis, irromper uma concepção totalmente diferente da estrutura ego-cogito-cogitatum da que fora dada através da sua articulação original da noese e do noema. Fora deste quadro, seja aqui mencionada, apesar dos muitos mal-entendidos que contém, a significativa Zur Metakritik der Erkenntnistheorie. Studien über Husserl und die phänomenologischen Antinomien, Stuttgard, 1956, de T. W. Adorno, mas também a crítica implícita acerca do carácter de absolutez da consciência na concepção de G. Funke da fenomenologia enquanto puro método, não implicando nenhuma metafísica, mas examinando criticamente os seus pressupostos.

${ }^{3}$ L. Landgrebe - "La phénoménologie est-elle une philosophie transcendentale?", in Études Philosophiques, 3(1954), pp. 315-323.

${ }^{4}$ L. Landgrebe - Husserls Abschied yom Cartesianismus, primeiramente publicado em Philosophischen Rundschau, 1961, depois em Der Weg der Phänomenologie, Güterloh, 1963, pp. 163-206.

${ }^{5}$ Publicadas em 1928, por Martin Heidegger, na redacção e composição que lhes deu Edith Stein, em 1917, as Liçôes sobre a Fenomenologia da Consciência lntenia do Tempo agrupam textos que vão desde 1901 até 1917 , inclusive. Patočka tem aqui em vista, porém, a data de 1904/1905, relativa ao curso sobre Hauptstiicke aus der Phänomenologie und Theorie der Erkenntnis, proferido em Gotinga, no Semestre de Inverno, em que o quarto 
Transzendentale Logik permaneceu essencialmente ancorada num cartesianismo do tipo acima caracterizado (como filosofia reflexiva da consciência).

Em que consiste, porém, a forma especificamente husserliana do cartesianismo? Quais as teses principiais que lhe são características? Que consequências gnosiológicas, que consequências metafísicas a elas se ligam? Um afastamento do cartesianismo significa, naturalmente, também um afastamento destas teses e das suas implicações. Ele encerra, contudo, ainda qualquer coisa mais, a saber, a tese sequente de que o cartesianismo significa uma torsão, uma interpretação errónea das intenções originais (não no tempo, ou pelo menos não apenas no sentido temporal) da fenomenologia. Neste caso, um afastamento do cartesianismo não traria consigo, de modo algum, um afastamento da própria fenomenologia enquanto tal, mas talvez até uma catarse e um reencontro do caminho de regresso a si própria.

O autor crê que estas questões - em sua opinião, não ainda expressamente levantadas - merecem uma reflexão pormenorizada. Foi Ernst Tugendaht que, sem fundamentar metafísico-ontologicamente a conexão com Descartes, apresentou de um modo mais preciso o cartesianismo husserliano enquanto pressuposto dogmático da doação absoluta das cogitationes. ${ }^{6} \mathrm{~A}$ questionação de Tugendhat, orientada para a teoria da verdade, não tem, porém, a fenomenologia enquanto tal como tema, e não se ocupa de uma possível transformação tanto da fenomenologia como da sua problemática.

A fenomenologia, que o seu fundador queria introduzir enquanto ciência filosófica fundamental, enquanto philosophia prima, é hoje um campo improdutivo. O rompimento com a fenomenologia da consciência realizado por Heidegger deu a ver a base metódica da fenomenologia, que deveria erguer a filosofia ao nível de uma ciência estrita, como abalada nos seus alicerces. Por outro lado, aquelas considerações que deram a base de partida de Husserl nas Logische Untersuchungen, as quais lhe permitiram descobrir a esfera específica dos modos de aparição, estão hoje em dia amplamente substituídas por investigações sobre a estrutura lógica da linguagem. ${ }^{7}$ Deve

"elemento capital" tinha como título "Zur Phänomenologie der Zeit", e cujos textos formam o núcleo essencial do trabalho publicado em 1928 [N. do T.].

${ }^{6}$ Enst Tugenhat - Der Wahrheitsbegriff bei Husserl und Heidegger. Berlin: Walter de Gruyter, $1970^{2}$, pp. 194 e ss. [N. do T.]

${ }^{7}$ Verosimilmente, Patočka refere-se aqui particularmente à primeira investigação, intitulada "Expressão e Significação". Nela, Husserl trata de problemas comuns a Frege e, um pouco mais tarde, a Bertrand Russell, relativos à teoria da linguagem e à semântica, no quadro de uma tentativa de fundamentação da lógica pura como base das matemáticas. A tradição de pensamento que haveria de nascer dos trabalhos de Frege, comummente designada por "filosofia analítica", chamaria, porém, a si quase exclusivamente o tratamento subsequente desses problemas, sem que a fenomenologia, orientada por uma outra compreensão do sentido que provém não só de Bolzano e de Frege, mas também da teoria da intencionalidade de Brentano, tivesse produzido algo de significativo neste domínio. Essa infecundidade do ponto de partida husserliano e da descoberta a que ele conduziu (o campo dos "modos de aparição", orientado pela teoria da intenção significativa e do preenchimento), 
este desmoronamento ser tomado como definitivo? O subjectivismo ameaçador foi afastado por Heidegger por meio da viragem para o ser. Mas não será o empreendimento de Sein und Zeit, de dar uma fenomenologia do ser-aí, do mundo, do intramundano, algo para repetir numa base nova? Não é, por outro lado, o esforço para produzir uma lógica do mundo pré-teórico algo fenomenologicamente relevante e que está dependente de uma reflexão fenomenológica ${ }^{8}$ Tudo isto são questões que se levantam quando seguimos no encalço do legado da fenomenologia clássica.

\section{I}

O que deu a medida para a posição peculiar das meditações de Descartes no problema da consciência não foi a suposta mania da certeza, como motivo existencial, mas sim a aceitação acrítica do esquema ontológico da essência e da existência (no sentido tradicional) e a sua aplicação à esfera do ser pessoal, introduzido por Descartes na filosofia teórica (nenhum princípio filosófico da filosofia antecedente vem formulado na primeira pessoa. As considerações paralelas de Agostinho situam-se ainda na encruzilhada entre filosofia e teologia).

A conclusão da dúvida cartesiana, ${ }^{9}$ na segunda meditação, que conduz ao ponto arquimediano de uma fundamentação da filosofia, consuma-se em dois passos, dos quais um responde à pergunta pela existência de um tal ponto arquimediano, o outro, à pergunta pela sua essência (essentia). Em certo sentido, a conclusão cartesiana mostra a prioridade da existência relativamente à essência; a existência, tal como é expressa no sum, existo, deve, porém, ser vista como acto de posição ou de realização da essência. O carácter pessoal do sum perde-se.

Perde-se no momento em que Descartes reconhece não saber ainda claramente o que é enquanto detentor da sua existência no modo da certeza. Ele diz, certamente com razão, que, doravante, deve ter muita atenção para não se tomar por outra coisa diferente daquilo que efectivamente é; mas, no mesmo instante, pergunta, de um modo inteiramente consequente, não por si próprio, pelo sum, mas antes pelas coisas, pois a cisão essência-existência é característica e válida das coisas, dos entes no mundo, dos entes de natureza impessoal. Aquilo de que Descartes se quer, portanto, saber diferente são as coisas, acerca das quais não é possível qualquer imediata certeza de ser; mas,

juntamente com a posterior quase total absorção desses problemas pela filosofia analítica são os factos a que Patočka pretende aqui aludir [N. do T.]

${ }^{8}$ Cf. H. Lipps - Untersuchungen zu einer hermeneutische Logik. Frankfurt, 1938, e o comentário de L. Landgrebe - Das Problem der ursprïnglichen Erfahrung in Werk von Hans Lipps, in Philosophische Rundschau IV (1956), $\mathrm{n}^{\text {os }}$ 3-4.

${ }^{9}$ Para todo o parágrafo, ver R. Descartes - Euvres de Descartes, ed. Adam-Tannery, vol. vII, pp. 26 e ss. 
desde o início, como resposta à sua pergunta, é uma coisa que é procurada enquanto sujeito de uma tal certeza. Por força deste começo metafísico tomado como algo por si mesmo compreensível, aquilo que é garantido pela certeza do cogito é desde logo uma coisa, isto é, um substrato duradouro de determinações tanto duradouras como mutáveis. No fundo, o ser, a existência é, tanto para esta como para qualquer outra coisa, algo exterior e sem conteúdo, enquanto simples acto de posição; daí que haja em geral necessidade de questionar em direcção a uma determinação mais clara do sum.

Ora é por si mesmo compreensível que o corpo, que o corporal e as suas determinações ("corpo" entendido no sentido puramente objectivo) sejam eliminados, mas também são riscadas por Descartes as determinações tradicionais da alma, como a nutrição e o movimento próprio. O mesmo é válido para a percepção enquanto função corporal. O que, por conseguinte, permanece como atributo constante, essencial, daquela coisa que eu sou só pode ser algo que, porquanto eu seja um Eu, se torne, a qualquer momento, precisamente minha determinação, determinação que não pode ser senão aquilo que, em todo o comércio com as coisas, deve ser pressuposto enquanto iniludivel e imediatamente presente, existam ou não as coisas respectivas, tenham elas efectivamente estas e aquelas determinações ou não; isto é, porém, o que Descartes designa com os termos "pensée, cogitatio". O que Descartes tem aqui em vista não é outra coisa senão aquilo em que o aparecente aparece [worin das Erscheinende erscheint], o campo fenomenal; por via das suas considerações orientadas pela diferença tradicional entre essentia e existentia, Descartes faz disso um atributo essencial da coisa que eu sou, um atributo que, marcado pelo carácter do ser-certo indubitável, é ele próprio cousal, isto é, constatável, objectivo, algo que se pode encontrar. Assim, a cogitatio só é possível porque o sum é a existentia de uma substantia cogitans, sendo o ego pensado ao modo de substrato e o cogito como atributo essencial. Este atributo essencial é concretizado como um affirmo, nego, concipio, dubito, volo, imaginor, sentio. Estas determinações são, numa parte, de natureza representativa (por exemplo, uma idea, presente no mente concipere, é qualquer coisa como uma imagem das coisas exteriores), e, na outra parte, são as minhas tomadas de posição, como volo, affirmo, nego. Nas tomadas de posição, é sublinhado o lado subjectivo-egológico, na ideia, o lado representativo. O campo fenomenal, em que o ente pode aparecer naquilo que é, deveio, assim, uma estrutura do "sujeito", que poderíamos tentar descrever com a fórmula moderna ego-cogito-cogitatum. Certamente, o cogitatum deve, então, entrar em cena duas vezes: uma, enquanto idea, outra, como a coisa que é exterior à esfera garantida no cogito. Mas porque a imediata certeza pertence ao definiens da subjectividade assim delimitada, esta não é pensável sem uma relação constante à auto-apercepção. É, por conseguinte, posta em destaque uma autocaptação reflexiva na certeza de si. 
Tal é, portanto, o sentido da tese segundo a qual o espírito é "mais fácil" de conhecer que o corpo e as suas determinações.

\section{II}

Estes motivos de pensamento chegaram até Husserl através da psicologia de Franz Brentano. Será útil, por conseguinte, mostrar brevemente em que consiste o cartesianismo de Brentano.

Como é bem sabido, Brentano fala de fenómenos psíquicos e físicos. ${ }^{10}$ Nele, o termo "fenómeno" designa, segundo Husserl, o objecto aparecente enquanto tal. ${ }^{11} \mathrm{O}$ fenómeno psíquico é, por conseguinte, aquele em que o objecto psíquico aparece. Que esta terminologia esconda dentro de si uma metafísica substancialista da alma é o que se pode comprovar pelas investigações de Brentano acerca da doutrina das categorias. ${ }^{2}$

Os fenómenos psíquicos distinguem-se dos chamados "fenómenos físicos" pelo facto de a sua presença garantir também a própria existência do psíquico, coisa que não acontece com os fenómenos "físicos"; distinguem-se ainda pela "inexistência intencional" ou "mental" do objecto, isto é, por via de um tipo peculiar de quase-relação a um objecto, o qual não deve ser aqui, certamente, tomado como termo de uma relação e que não é, de modo algum, por conseguinte, um ente independente. Primariamente, esta relação não é própria senão das representações,,$^{13}$ pois os outros tipos de relação intencional, como os juízos e os fenómenos afectivos, são tomadas de posição perante o objectual apresentado originária e primariamente na representação. Não tomando agora em consideração o facto de Descartes não distinguir aqui os lados mental e não mental, é completo o paralelismo com as determinações cartesianas, tanto com as ideae como com os juízos e as representações volitivas.

A garantia da existência dos fenómenos psíquicos não se aplica simplesmente a estes, mas também ao real substancial que neles se manifesta. É preciso distinguir, nomeadamente, os fenómenos psíquicos enquanto tais e o estado psíquico concreto, também denominado "acto", que é uma contextura formada por toda a sorte de fenómenos e que contém uma relação secundária com a realidade psíquica, sob a forma de uma representação e de um juízo sobre si próprio. É próprio deste juízo uma evidência imediata de reconhecimento [Anerkennung]. ${ }^{14}$ Nesta "percepção interna", os fenómenos psíqui-

10 Franz Brentano - Psychologie vom empirischen Standpunkt. $2^{\mathrm{a}}$ edição, Leipzig, 1925.

11 Edmund Husserl - Logische Untersuchungen. II 1, $2^{a}$ edição, Halle, 1913, p. 371.

12 Vide Franz Brentano - Kategorienlehre. Leipzig, 1933, p. 161, e Psychologie, Vol. 2, pp. 138 e ss.

13 Fr. Brentano - Psychologie, Vol. II, p. 127.

14 Idem, p. 139. 
cos são captados como imediatamente existentes. Por outro lado, esta percepção interna oferece a base para uma ponderação da sua estrutura substancial (determinações que pressupõem, por fim, um substrato individual, mesmo que não esteja espacialmente individualizado)..$^{15}$

Vemos assim que todos os elementos fundamentais do cartesianismo retornam, em Brentano, nos problemas da consciência e da alma. A notável diferenciação entre ideias e tomadas de posição, estabelecida por Descartes no plano fenomenal, é agora levada tão longe por Brentano que é mesmo admitida uma contrapartida "subjectiva" para as ideias, chamada "representação", que é um simples tomar [Hinnehmen] enquanto algo intencional, cuja apreensibilidade exige qualquer coisa como uma "percepção interna". Nesta "evidência da percepção interna", surgiu novamente o cogito cartesiano, o qual garante tanto o ser como o ser-assim [Sosein] do objecto imanente.

A diferença relativamente a Descartes é, por consequência, a seguinte: à substância anímica, à coisa "eu", não a capto, segundo Brentano, imediatamente, mas apenas nos fenómenos, que estão certamente dados como seres na evidência imediata - este é o sentido do cogito — e capto a substância anímica porquanto apreendo esses fenómenos, originariamente afirmados [bejahten] na evidência da percepção interna, enquanto atributos de um substrato, de uma substância. Também como em Descartes, o "sum" eclipsa-se completamente; a garantia de existência respeita a estruturas despersonalizadas, captáveis na sua generalidade, como representações e seus objectos, teses, etc.; a própria coisa anímica, enquanto substrato, é algo cuja individualidade e, por conseguinte, ser-próprio nunca está dado originariamente. $\mathrm{O}$ "mental", o "psíquico", recolheu em si tantos caracteres do plano fenomenal, onde o cousal e o pessoal mutuamente se encontram, que o pessoal foi totalmente esmagado. Este desaparecimento mostra-se precisamente na duplicação reflexiva do fenomenal por fenómenos "intencionais" como a representação (de um representado).

\section{III}

Por meio de uma crítica da terminologia de Brentano, ${ }^{16}$ Husserl tentou não apenas esclarecer a situação, mas, a partir da raiz, torná-la frutuosa para os seus objectivos, a saber, a "elucidação do conhecimento". Não se trata, por conseguinte, em Husserl, de uma questionação em torno da psicologia e dos seus fundamentos metafísicos, como em Brentano, mas antes de um problema de "teoria do conhecimento". Nas Logische Untersuchungen, a palavra "teoria do conhecimento" não deve, contudo, ser entendida no senti-

15 Idem, p. 161.

${ }^{16}$ E. Husserl - Logische Untersuchungen, II. $1^{\text {a }}$ parte, p. 370. Aí, Husserl renuncia à distinção entre fenómenos psíquicos e físicos, mas continua falando de uma relação intencional. 
do que era corrente nesse tempo, a saber, no estilo do esclarecimento lógico, impulsionado pelos neo-kantianos, dos pressupostos subjacentes à ciência directamente ligada às coisas, pressupostos que são invocados a título de condições de possibilidade do seu conhecimento. Trata-se, para Husserl, de algo totalmente diferente: das mais elementares e simples questões do próprio acesso público às coisas, primeiro que tudo das formações lógicas na sua objectividade, elaborada nos Prolegomena. As objectividades devem ser acessíveis, devem aparecer de um certo modo, devem ser dadas de modos determinados, enformados por uma lei. $\mathrm{O}$ "esclarecimento fenomenológico do conhecimento" significa uma coisa totalmente diferente das condições transcendentais de possibilidade do a priori, implicado no objecto de conhecimento e a elaborar regressivamente numa conclusão a partir deste. Isso é particularmente manisfesto aqui, onde Husserl ainda não usa de modo algum a linguagem do transcendentalismo. $\mathrm{O}$ esclarecimento fenomenológico do conhecimento visa aquilo que torna possível que o objectivo apareça de modos diferentes, primeiro que tudo e de uma maneira central, porém, que ele apareça como ele próprio e se mostre enquanto tal naquilo que é, tanto no seu núcleo como no seu sentido, ou melhor, nas diferentes formações de sentido, nos seus caracteres posicionais e nas suas modalizações, nos seus modos de doação. ${ }^{17}$ A descoberta própria das Logische Untersuchungen foi este campo do mostrar-se [Sich-Zeigens], campo que, para que a própria coisa possa posicionar-se e aparecer, deve ultrapassar tanto a coisa como a estrutura cousal que lhe é própria e conter em si mesmo uma legalidade de tipo peculiar, que não é recondutível nem à do objecto no seu ser próprio, nem à do ser mental no seu carácter especificamente egóico. Esta legalidade é uma estrutura cuja compreensão é indispensável ao eu, ao "sujeito", caso ele deva existir na clareza relativamente a si próprio e às coisas, estrutura que, porém, não precisa de ser por causa disso, de forma alguma, uma estrutura do sujeito. Para tematizar esta esfera da aparição e suas legalidades, Husserl precisa, porém, de meios conceptuais que a tradição só escassamente the pode oferecer. Interessa-lhe falar de actos intencionais e da objectualidade que lhes está coordenada para poder evitar, tomando certas cautelas, a confusão do subjectivo e do objectivo comum na psicologia coeva, sob influência do empirismo. Quando fala das "vivências" e do seu "carácter intencional", não visa, no fundo, o subjectivo no sentido do egóico; nem sequer reconhece nesta altura a existência de um eu "puro". Visa, no fundo, estruturas na esfera de aparição, por conseguinte, em certo sentido, de novo estruturas "objectivas", fazendo-o, no entanto, a partir de uma nomenclatura tomada em grande parte de Brentano. Isto é particularmente visível aí onde

17 Acerca disto prestam um testemunho concludente sobretudo as investigaçōes fundamentais do segundo tomo das Logische Untersuchungen, particularmente a quinta e sexta investigações. 
ele defende a concepção de Brentano acerca dos actos intencionais contra outras opiniões - sobretudo a de Natorp, que se exprime contra a realidade supostamente verificável de um correlato mental de uma representação objectiva - e se esforça, portanto, por concretizar a sua concepção do intencional. $^{18}$

Quando Natorp diz: ${ }^{19}$ «A existência [do som] para mim é a consciência que tenho dele. Se alguém quer surpreender a sua consciência ainda de outro modo que pela existência de um conteúdo para si, então eu [...] não posso seguir o seu exemplo», Husserl tenta, através de exemplos concretos, pôr-lhe diante a doação do acto e, por esse meio, legitimar o acto enquanto realidade subjectiva. Procura fazê-lo por via de uma explicação mais profunda do conceito de "existência de um conteúdo para mim". Há diferentes modos do notar: um conteúdo está aí para nós de um modo diferente quando está simplesmente implícito e quando é captado como algo explicitamente destacado. Por fim, chama-se a atenção para a diferença entre sensação e percepção: «diferentes actos podem percepcionar o mesmo e, porém, sentir coisas diferentes» e, por outro lado, diferentes actos podem apreender de modos diferentes as mesmas sensações. Afirma-se que a própria apreensão não é nenhuma afluência de novas sensações, mas antes um "carácter de acto", um "modo da consciência", "da disposição". Um exemplo da esfera preponderante da percepção visual fala de uma caixa que vejo de diferentes lados e que permanece a mesma nesses diferentes aspectos. Vivemos aí a "consciência de identidade", um procurar captar a identidade. São certamente oferecidos, de um e do outro lado (para duas rotações diferentes da caixa), diferentes conteúdos de sensação, os quais são, porém, apreendidos no "mesmo sentido", a apreensão (apercepção) segundo este "sentido" é um carácter da vivência que produz, por vez primeira, a "existência do objecto para mim". Um outro campo de exemplos é produzido a partir da comparação da percepção com a recordação e de ambas com a prefiguração [Vorbildlichung] (por exemplo, por meio de pinturas, estátuas, etc.), mas sobretudo pela comparação com as expressões linguísticas [Ausdriicke]. Qual a diferença entre os arabescos e a consciência propriamente simbólica, que a eles se liga, mas onde a compreensão do teor significativo que aí se liga eclipsa os arabescos? Em que consiste, particularmente, a consciência significativa vazia de uma palavra que ouvimos na conversação, sem tornar intuiva a coisa que ela nomeia, mas sabendo, porém, daquilo que se trata? Em resumo: as sensações e os actos que as "apreendem" ou "apercebem" são vividos, mas não aparecem objectivamente; eles não são vistos, ouvidos, percepcionados por um qual-

18 Idem, pp. 359 e ss, particularmente pp. 380 e ss.

19 Com pequenas modificações em algumas frases, este texto é comum ao artigo de 1971, "O subjectivismo da fenomenologia de Husserl e a exigência de uma fenomenologia assubjectiva", antes traduzido [N. do T.]. 
quer "sentido". Por outro lado, os objectos aparecem, são percepcionados, mas não são vividos.

Temos aqui perante nós o subjectivismo da fenomenologia husserliana em estado nascente. O que a amostragem do "lado subjectivo" dos "actos" deve trazer à luz são aquelas estruturas que, não se podendo apoiar numa pré-doação "intuitiva", carecem, porém, de um "apoio", pois não têm nenhuma significação "cousal" no sentido propriamente reico [im eigentlich-realen Sinne], não representam alguma coisa no espaço-tempo reico nem pretendem ter aí uma existência - o inintuitivo, o modo "impróprio", "deficiente" de doação é, aqui, tomado como índice do subjectivo. Nestas reflexões, não está ainda presente a doutrina husserliana acerca da correlação do lado objectivo (mais tarde: "noemático") com o lado subjectivo (mais tarde: "noético"). Mas estas reflexões são a água-mãe a partir da qual eles são cristalizados.

Com efeito, uma elaboração mais pormenorizada da doutrina dos modos de doação deveria conduzir à visão segundo a qual também o "inintuitivo", o aparecente num modo deficiente de doação, é um ser - não certamente um ser no sentido subjectivo-egóico -, pois como poderíamos de outro modo conceber as sínteses de identificação a que sempre de novo se chega no falar, no conhecimento e no reconhecimento do mesmo? É, pois, o mesmo objecto que uma vez se mostra de modo deficiente e, a seguir, no modo da autodoação. E a síntese não é outra coisa senão este mostrar-se do mesmo, a presença do idêntico em e apesar de diferentes modos de doação. No que respeita às "apreensões", estarão elas, de facto, presentes como vivências, como modos de disposição e, por conseguinte, como algo captável no volver-se reflexivo, ou estarão elas presentes, ao contrário, objectivamente, no ir directo em direcção às coisas? É bem de uma aparição objectiva que se trata quando, com diferentes intuições dos lados da caixa, tenho apesar disso diante de mim o mesmo objecto. E será o vermelho da caixa, de facto, analisável em duas coisas, nomeadamente, na impressão de vermelho e na sua apercepção objectiva enquanto coloração da caixa? Ou é o vermelho da caixa, de um lado, um mediador objectivo, que a si próprio se retira para um plano de fundo, e, por outro lado, um objecto que se nos depara como independente? Onde está aí qualquer coisa que possa ser percebida como um "animar" de uma estrutura de dados? Talvez ambos os modos de aparição objectiva se fundem um ao outro reciprocamente, mas eles fazem-no precisamente porque são ambos objectivos.

Que ocorra aqui um mal-entendido funesto, é um ponto de vista que se impõe inevitavelmente. As "apreensões", etc., são tidas como garantidas, enquanto vivências subjectivo-reais, porque aos caracteres cousais, que são propriamente visados, nada corresponde que seja independente e reico. Mas porque o olhar daquele que percorre esses caracteres, que persegue a sua articulação e conexões de fundação, faz tudo isso na evidência da simples 
doação, e porque se designa esses caracteres como "subjectivos", a própria experiência é designada precisamente como captação de algo subjectivo. À captação do ente subjectivo, à reflexão sobre a subjectividade é agora atribuído aquilo que, enquanto carcácter de evidência, é próprio da esfera da aparição na sua função de mostrar e mostrar-se. A esfera fenomenal, o campo daquilo que mostra e, neste mostrar, ao mesmo tempo se mostra, não pode ter o carácter problemático que é próprio do objecto que aí se mostra, remetido para sempre mais experiências e cuja confirmação nunca chega, por conseguinte, ao fim; pois esta remissibilidade do que é da ordem do reico é precisamente algo que se joga na esfera fenomenal, cuja clareza é justamente um pressuposto para este carácter problemático do objecto que se mostra e demostra [sich zeigt und ausweist]. Se a investigação da esfera fenomenal é interpretada como reflexão subjectiva, será então, naturalmente, próprio da reflexão o carácter de captação em original do ser subjectivo: esse ser "não se adumbra", mostra-se simplesmente naquilo que é. Por conseguinte, desde o início se cinde a esfera fenomenal em dois momentos - de um lado, o aparecente nos seus modos de doação, do outro, os supostos fundamentos subjectivos deste aparecer. Descrevem-se estes últimos enquanto vivência, que está dada para o olhar reflexivo, e atribui-se, por fim, a este olhar reflexivo aquela evidência que é própria do mostrar e do mostrar-se do campo fenomenal, da própria aparição no seu aparecer. A cisão acima mencionada, que se inicia primeiro com os modos de doação inintuitivos, deficientes, privados da presença da própria coisa, é generalizada. Por um lado, admite-se certamente que o inintuitivo também pertence ao lado objectivo, mas, por outro lado, assim que a duplicação subjectiva é consumada, esta é ela própria generalizada, e assim nos encaminhamos para uma correlação universal "essencialmente válida", a qual, mais tarde, aparecerá como doutrina da coordenação de essência entre a noese e o noema.

Está agora também aberto o caminho para uma retomada da marcha cartesiana da dúvida, efectuada agora de um modo especificamente novo, que permite evitar os saltos metafísicos depois da sua feliz chegada ao ponto arquimediano. Husserl descobriu a esfera fenomenal, a esfera do mostrar-se no seu aparecer, a esfera que, na tradição filosófica anterior, sempre foi, quando referida, imediatamente reconvertida nas estruturas do ente que se mostra na sua particularidade. Ele tenta agora destacar esta esfera e assegurá-la metodicamente, por meio de uma notável analogia com a marcha cartesiana da dúvida. É desde logo claro que a legalidade do aparecer no seu aparecer não pode, de modo algum, ser a legalidade do aparecente nas suas estruturas próprias, particularmente nas suas relações causais. Não posso recorrer ao aparecente para clarificar a aparição no seu aparecer, porque, para toda e qualquer tese acerca do ente aparecente, está já pressuposta a compreensão do aparecer. É, por conseguinte, uma sã máxima metódica excluir em toda a amplitude da sua extensão todas as teses a respeito do ente 
aparecente no seu ser próprio, não as utilizar, pô-las fora de acção, se se quer descobrir o aparecer enquanto tal, assegurá-lo e investigá-lo na sua essência própria. Esta não utilização não é uma simples abstracção do aparecente no seu ser próprio, pois este deve ser mantido diante do olhar precisamente como aquilo que se mostra e demostra. Apenas se deve estar ciente que tematizar o ente nas suas estruturas próprias, por exemplo, enquanto realidade entre outras realidades, significa uma coisa completamente diferente que tematizá-lo no seu aparecer, por referência ao seu mostrar-se. O nosso intento aponta, portanto, para o aparecer enquanto tal, para a esfera fenomenal. Este intento é, porém, esboçado com termos que provêm da esfera subjectiva: fala-se de uma redução à pura imanência em vez de uma exposição do campo de aparição enquanto tal. ${ }^{20} \mathrm{O}$ problema, inicialmente levantado como problema da não inclusividade da esfera fenomenal nas realidades e idealidades, nas coisas na sua independência, volve-se agora no problema da não inclusividade real [reell] das coisas na esfera subjectiva das vivências. Enquanto inicialmente se via que, na esfera fenomenal, que se dá directamente, há relações como as do objecto mediador e mediado, do objecto em modos diferentes de doação, etc., fala-se agora do objectivo enquanto aparecente na vivência e transcendente perante a corrente real [reell] de vivências. Enquanto, inicialmente, "subjectivo" era tomado, num sentido completamente corrente, como o fenomenal (portanto, "objectivo") que toma em consideração a perspectividade, o modo de doação, o acesso, os caracteres posicionais modalizantes, por contraposição à coisa em si mesma (que é aperspectivística), o subjectivo, enquanto vivência, é agora distinguido do fenomenal aparecente na vivência. E o problema já não é: como se deve analisar e descrever o aparecer enquanto tal, a relação das perspectivas e modos de doação com o que é dado nestes? O problema é agora estoutro: como."se constitui" a objectividade aparecente na vivência dada reflexivamente na sua originariedade, sem perspectivas, de modo absoluto, e na conexão contínua das vivências, na "corrente de consciência"? A subjectividade - fantasma autoproduzido pela consideração duplicativa dos modos de doação - engoliu e fez desaparecer o problema da aparição enquanto tal e, com ele, o problema do plano fenomenal na sua independência, no qual o ente, tanto de natureza egóica como não-egóica, se mostra naquilo que é e onde os dois tipos de ente se podem mutuamente encontrar. Ocorreu um notável retorno a Descartes, no qual nada mais resta do "sum" existente. Em vez disso, a cogitatio enquanto tal, na sua essência (essentia), recebeu uma extensão tal que a "autocerteza da consciência" diz respeito e designa exclusivamente esta essência. Do "sum" apenas permanece um parco resquício no facto de toda e qualquer

${ }^{20}$ Cf. E. Husserl - Die Idee der Phänomenologie. Husserliana II, Den Haag, 1950. Camparando com as exposições posteriores, por exemplo, nas Ideen I, aqui a redução não é ainda conduzida de um modo tão universal, mas esta obra mostra, talvez, com mais clareza o motivo da redução. 
corrente de consciência ser algo individual, um ser-para-si; resquício em todo o caso assaz embaraçoso, porque como se deve, então, captar de um modo originário (e não simplesmente problemático) o outro eu, ao mesmo tempo constituído e constituinte, e precisamente enquanto constituinte? Este é um daqueles problemas a respeito dos quais desesperaram também aqueles fenomenólogos que aceitaram o subjectivismo da doutrina da redução, problemas perante os quais se sentiram forçados a abandonar as doutrinas do mestre."1

Contudo, no fundo, o problema da constituição é, no seu todo, insolúvel. Como começa propriamente a vivência enquanto tal, originariamente a si mesma dada na reflexão, para deixar depois aparecer, do lado objectivo, uma transcendência - tudo isto não pode ser observado, mas apenas admitido como facto. Contra isso nada se poderia objectar se se tratasse de um facto último, autêntico, acessível para a intuição, e não de uma construção. A redução à imanência pura e a constituição, que dela se segue, da objectividade na consciência purificada, despida de toda e qualquer tese mundana que ponha um ente objectivo, não se serviu inadvertidamente, para se estabelecer, de uma pequena parcela do mundo, mas antes de uma teoria grosseiramente metafísica, pois a subjectividade, a cuja imanência ela finalmente recorre, só se tornou possível através da cisão da esfera fenomenal enquanto tal, e esta cisão aconteceu devido ao facto de não se ter visto como se poderia pensar a esfera fenomenal enquanto qualquer coisa independente e, por via disso, se ter sido obrigado a pôr-lhe por baixo qualquer coisa da ordem do reico [Reales] (as "apreensões", os "actos idênticos", etc.). Esta realidade, inicialmente modesta, fez de seguida, porém, uma carreira surpreendente, pois, de ente no mundo que era, tornou-se depois na substância da própria constituição do mundo.

Que as coisas sejam de facto assim e que a posição do problema na fenomenologia "transcendental", que assenta na redução à pura imanência, assente numa cisão dos modos de aparecer em objectivos e subjectivos e na duplicação que aí se inseriu - para isso possuímos um testemunho muito característico e convincente nos factos comunicados por Ingarden sobre o problema dos chamados "dados hiléticos". Ingarden diz-nos, de um modo que não deixa espaço para dúvidas, que Husserl hesitou longamente acerca da questão de saber se estes dados - que, por um lado, pertencem à complexão real das vivências enquanto tais e, por outro, porém, se dissolvem no constituído enquanto suas partes e momentos - pertencem ao lado noético ou ao lado noemático da vivência..2 A dupla função dos "dados sensíveis", que

${ }^{21}$ Cf. A. Schütz - Le problème de l'intersubjectivité transcendantale chez Husserl", in Cahiers de Royaumont III, Paris, 1959, pp. 334 e ss. Ver, no mesmo volume, a intervenção de E. Fink, pp. 369-373.

22 E. Husserl - Briefe an Roman Ingarden. Phænomenologica, vol. 25 (editado por Roman Ingarden), Den Haag, 1968, p. 128. 
surgem, uma vez, na complexão subjectiva, outra, na conexão das coisas, é aí muito clara e permite pôr o dedo na cisão que se liga a este duplo contexto. Husserl faz aqui qualquer coisa de análogo aos teóricos do "monismo neutral": ele permite que o mesmo apareça duas vezes em diferentes conexões significativas. Que isto seja, contudo, completamente inadequado para o problema da aparição enquanto tal, é coisa que desde logo se torna para ele clara, porque a "conexão objectiva" deve aparecer precisamente no que é subjectivo e ambos devem, por conseguinte, estar presentes ao mesmo tempo, coisa que, portanto, duplica os dados. Todas estas dificuldades surgem da obstinação de Husserl em não ver na sua independência a esfera do aparecer do ente aparecente, o campo da aparição, que ele próprio descobriu, e em reconduzi-lo ao ente aí aparecente, coisa que deve levar, por fim, à desaparição da fenomenologia enquanto doutrina do aparecer.

Possuímos ainda um testemunho, provindo do próprio Husserl, sobre esta situação crítica da fenomenologia causada pela construção subjectiva das cogitationes. É o $§ 50$ da Krisis, trabalhado e apresentado por Iso Kern na sua novidade relativamente aos anteriores programas fenomenológicos. Em vez de dar ênfase às cogitationes, ao cogito, na triplicidade ego-cogito-cogitatum, trabalha aí Husserl, de modo inesperado, exclusivamente com o ego e os cogitata. O "sum" é, deste modo, de novo trazido à luz. Tarde demais, porém, na carreira de Husserl, para que possa ganhar ainda uma figura concreta. O "subjectivo", o egóico, não na figura objectivada de uma noese a captar originariamente no olhar "reflexivo", mas precisamente enquanto ser-eu [Ichsein] na mobilidade originária, prepara a sua irrupção, de tal modo que o problema da sua relação ao plano fenomenal deve, manifestamente, ser posto em bases novas. Husserl deve, por conseguinte, ter acabado por ver a situação da fenomenologia subjectiva, se bem que não tenha tido, manifestamente, afoiteza para sacrificar a metafísica idealista da consciência, que defende ainda ao tempo da Krisis e que provém exclusivamente da subjectivação artificial do fenomenal. Seria talvez de considerar como execução da última vontade do criador da fenomenologia cumprir efectivamente esta catarse do fenomenal e devolver à fenomenologia, por esta via, o sentido dessa pesquisa do aparecer enquanto tal que constituía, porventura, a intenção original do seu fundador.

\section{IV}

A "esfera fenomenal" não é subjectiva no sentido de que fosse composta a partir de processos subjectivos, de "intenções animadoras", de "apreensões" e de todo o tipo de vivências, ou que fosse "constituída" nelas enquanto correlato noemático de uma noese dada na evidência da autocaptação absoluta. Ela é certamente subjectiva, mas num sentido muito mais simples: ela não coincide com o ente em si, ela é, de um certo modo, mais vasta, mais 
abrangente, ela é o projecto [Entwurf] de todo o encontro possível com o ente. Enquanto projecto de um encontro possível, tem ela naturalmente conexão com o ente que vive nas possibilidades, que é enquanto possível, e é precisamente isso aquilo que o "sum" quer dizer. O ente egóico não tem quaisquer propriedades constatáveis, coisa que não significa, de modo algum, que ele seja um nada, algo indeterminado; a sua determinidade assenta na sua situação e no seu fazer. Vivendo nas possibilidades, isto é, colhendo-as e identificando-se com elas, deve ele projectar o esquema de todo o ente possivel, e certamente num sentido semelhante àquele em que um artista projecta um conto ou uma pintura, isto é, de um modo puramente cousal, sem os entretecer a partir de "vivências" próprias. Apesar disso, a esfera fenomenal não é de modo algum solicitada enquanto criação do sujeito, enquanto seu lance [Wurf] arbitrário, e, por conseguinte, também não é subjectiva neste sentido radical. Porque ela é concebida em vista do aparecer do ente em própria pessoa, ela deve, por conseguinte, ser codeterminada por ele, pela sua constituição enquanto ente. Acima de tudo, porém, o mostrar-se nela [na esfera fenomenal] não é nenhuma obra humana, porque isso pode tão pouco ser produzido pelo homem como o seu ser próprio e sua "Iuz", a transparência que lhe é própria, o interesse por e a compreensão deste ser próprio. No ser próprio está o ser em obra. No "sum", no "eu sou" e nas estruturas correlativas a ele pertencentes, entra o ser em aparição e, no projecto da esfera fenomenal, oferece ele a todo o ente a claridade do seu espaço. Por essa razão, com a entrada na esfera fenomenal, o ente não se aliena de si próprio, ele não se transforma numa subjectividade que lhe seja em essência estranha; quando ele efectivamente se muda para um novo contexto, para o contexto do aparecer, muda-se apenas em si mesmo; aqui, nesta esfera, o ser, enquanto seu próprio ser, é devolvido àquele ente que, originariamente, está completamente distante de si mesmo e permanece estranho a si mesmo.

Num certo sentido, a esfera fenomenal deve ser, de facto, fundada no ego, ou melhor, no sum, no qual o ego está contido. Mas não se aprende a fundar a esfera fenomenal sobre o ego tentando, com isso, olhar absortamente para ele, porque "no" ego, propriamente dito, nada há para ver. Vemos o ego, ou melhor, o ego só se pode tornar visível através daquilo com que se ocupa, daquilo que projecta e faz precisamente na esfera fenomenal. A esfera fenomenal projecta o ente possível, não na abstracção de um ser-em-si, mas antes precisamente em conexão com o "sum". Ela é bem um projecto do ente em totalidade, que engloba o ego sum e certamente enquanto sum, isto é, como um centro que se refere a si mesmo através de tudo o resto. A função vital, originalmente prática, da esfera fenomenal reside em tornar possível este encontro consigo mesmo. O fenómeno não é nenhum eu, ele é cousal, mas está trasbordantemente preenchido de caracteres que tornam o ego visível porquanto lhe põem diante as possibilidades do seu ser, de 
tal modo que se pode dizer que não conhecemos o modo como o objecto se constitui pela consideração do subjectivo, mas, ao contrário, aprendemos, como que em negativo, a conhecer o sujeito pela consideração do objectivamente fenomenal.

Esta análise da esfera fenomenal, do aparecer no seu aparecer, fundada no "sum", pode, apesar disso, ser denominada com boas razões como "assubjectiva". Ela evita a pontualidade do ego, que, para o transcendentalismo kantiano, não só se tornou a pedra de alicerce das sínteses da consciência, mas também pôs o selo de lacre no seu fechamento subjectivo da fenomenalidade "pura e simples". A pontualidade foi também evitada pela fenomenologia husserliana porquanto ela tentou reconduzir - sem dedução, mas no puro e simples mostrar - o aparecer às prestações de uma subjectividade fluente [einer strömenden Subjektivität]. Apesar disso, esta foi sacrificada no altar do subjectivismo. Pela apreensão do ego enquando índice pessoal no sum, pode-se avançar mais além, nomeadamente, até ao ser, cujo traço essencial interno é o ser-em-cada-caso-meu [Jemeinigkeit]. O ego não é, por conseguinte, nada mais que o carácter de ser do ente que está interessado no seu próprio ser, que existe temporal e motilmente. Coisa que reenvia mais além ainda, por sobre a esfera da egoidade. $O$ resultado obtido por uma análise radical da esfera fenomenal aponta na direcção de um tempo originário, não de uma simples vivência do tempo, mas sim do tempo enquanto tal.

A fenomenologia assubjectiva sobe, assim, até dimensões que eram inacessíveis à fenomenologia subjectiva, dimensões estas que não fecham, mas antes abrem. Por outro lado, está ela capacitada também para descer até à análise daqueles movimentos da vida que o nosso "sum" consuma e em cujo transcurso a esfera fenomenal adquire a sua configuração concreta. $\mathrm{O}$ "ego sum" deve ganhar o seu posto firme entre as coisas e os homens, enraizar-se, para um dia participar, consumindo a sua substância, na resistência à afluência do mundo; neste movimento, ele deve concordar com a perda da sua própria essência, para talvez um dia a recuperar.

Acima de tudo, devem as indicações anteriores dar expressão à concepção segundo a qual a transformação, empreendida por Heidegger, do bosquejo husserliano original da fenomenologia não significa, talvez, um derrube da intenção fundamental desta disciplina, tal como o seu fundador originalmente a concebeu, mas que tal transformação estará, porventura, mais perto desta intenção do que o fundador da fenomenologia no seu período "transcendental". Partindo do "sum", através do seu destaque ontológico perante o ente que não é segundo o modo do Dasein, tornou-se possível irromper, para lá do ego, até estruturas mais fundamentais, que são fundadoras da experiência. Esta irrupção, em sentido próprio, só é por vez primeira conseguida nos tempos tardios da chamada "Kehre"; nela se mostra pela primeira vez o ser que, no "sum", chega no movimento e na eficiência iluminadora desta obra fenomenalizante. Ela forma, porém, juntamente com o 
projecto "antropológico" de Sein und Zeit, uma unidade em cuja prossecução seria talvez possivel tratar todos os problemas da fenomenologia que também se afiguraram a Husserl. Além disso, deve ser acentuado que o fecho subjectivo do ente, consumado pelo idealismo, é aqui principialmente evitado, e que o ponto de partida fenomenológico readquire o significado daquele magno afastamento do subjectivismo em que acreditavam os discípulos de Husserl em Gotinga. Talvez a tentativa aqui apresentada de uma reflexão crítica logre pôr-nos diante dos olhos a lógica interna destas relações de um modo algo mais claro do que é habitualmente o caso. 